\title{
Eriocaulaceae no Parque Nacional do Itatiaia, Brasil
}

\author{
Eriocaulaceae from the Itatiaia National Park, Brazil
}

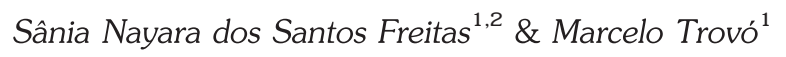

\begin{abstract}
Resumo
Os trabalhos florísticos em Eriocaulaceae estão concentrados na Cadeia do Espinhaço, o principal centro de diversidade da família. O presente trabalho teve como objetivo realizar o tratamento florístico de Eriocaulaceae no Parque Nacional do Itatiaia, contribuindo com o conhecimento da família na Serra da Mantiqueira, um importante centro de diversidade do grupo no Brasil. Com base em expedições de campo e análise de espécimes de herbário, foram encontrados quatro gêneros e nove espécies, das quais sete são endêmicas da Serra da Mantiqueira. Todas as espécies são terrestres e restritas às áreas mais secas das formações campestres da parte alta do parque, exceto Eriocaulon majusculum, que ocorre nos brejos de altitude. Fazem parte do manuscrito: uma chave de identificação para as espécies, além de descrições, comentários e documentação fotográfica.

Palavras-chave: flora, Mantiqueira, Paepalanthoideae, Poales, taxonomia.
\end{abstract}

\begin{abstract}
The Eriocaulaceae floristic surveys are concentrated in the Espinhaço Range, the family main center of diversity. This manuscript aimed to survey the Eriocaulaceae from the Itatiaia National Park, increasing the knowledge of the family in the Mantiqueira Range, a relevant Eriocaulaceae center diversity in Brazil. Based on field expeditions and herbarium analysis, four genera and nine species are recorded, being seven of them endemic to the Mantiqueira Range. All species are terrestrial and restricted to the open formations of the high parts of the park, except Eriocaulon majusculum, which occurs in the high altitude swamps. The manuscript contains an identification key for the species, along with descriptions, comments, and photos.
\end{abstract}

Key words: flora, Mantiqueira, Paepalanthoideae, Poales, taxonomy.

\section{Introdução}

Eriocaulaceae compreende 10 gêneros e cerca de 1.200 espécies, distribuídas predominantemente na região Neotropical (Stützel 1998; Giulietti \& Hensold 1990; Giulietti et al. 2012). Os principais centros de diversidade da família são os Tepuis e a Cadeia do Espinhaço (Stützel 1998; Giulietti \& Hensold 1990). A família é caracterizada por possuir inflorescências capituliformes com flores diminutas, geralmente unissexuadas e folhas dispostas em roseta (Stützel 1998; Ruhland 1903; Koernicke 1863).

No Brasil, ocorrem 625 espécies de Eriocaulaceae, sendo 558 endêmicas (BFG 2015).
Os esforços florísticos ainda são escassos e em sua maioria voltados aos principais centros de diversidade da família (Costa et al. 2008; Hensold 1999). No entanto, outras regiões que possuem significativa riqueza de espécies ainda são pouco estudadas. Um exemplo é a Serra da Mantiqueira, que conta apenas com listagens preliminares que registram cerca de 50 espécies (Sano \& Giulietti 2012; Trovó et al. 2015) e três tratamentos florísticos que tratam a região parcialmente. São eles: a Flora fanerogâmica do estado de São Paulo (Sano \& Giulietti 2012), a flora do Parque Estadual do Ibitipoca (Ferreira et al. 2011) e a flora do Parque Nacional da Serra do Caparaó (Trovó et al. 2007).

\footnotetext{
${ }^{1}$ Universidade Federal do Rio de Janeiro, Inst. Biologia, Depto. Botânica, Lab. Integrado de Sistemática Vegetal, CCS, B1. A1, Cidade Universitária, 21941-590, Rio de Janeiro, RJ, Brasil.

${ }^{2}$ Autor para correspondência: sanianayara@hotmail.com
} 
Com o intuito de aumentar o conhecimento acerca das Eriocaulaceae ocorrentes na Serra da Mantiqueira, este estudo tem como objetivo realizar o tratamento florístico das espécies da família que ocorrem no Parque Nacional do Itatiaia. Foi elaborada uma chave de identificação para as espécies, assim como descrições detalhadas, fotografias e comentários. Espera-se que este trabalho possa servir de base para estudos posteriores e para a conservação da família na área.

\section{Material e Métodos}

O Parque Nacional do Itatiaia está inserido na Serra da Mantiqueira e abrange as cidades de Itatiaia e Resende, no Rio de Janeiro; Itamonte, Alagoa e Bocaina de Minas, em Minas Gerais; fazendo ainda limite com o estado de São Paulo (Brade 1956; ICMBIO 2015). Foi o primeiro Parque Nacional do Brasil, tendo sido fundado em 14 de junho de 1937. Abriga hoje uma área com cerca de 30 mil hectares, com uma vasta riqueza hídrica, florística, além de abrigar muitas espécies da nossa fauna (ICMBIO 2015). O Parque está inteiramente no bioma Mata Atlântica, e sua composição florística varia de floresta ombrófila densa montana e alto montana até os campos de altitude, onde encontram-se diversas espécies herbáceas associadas a formações rochosas (Veloso et al. 1991).

O trabalho foi realizado em toda extensão do Parque Nacional do Itatiaia, em especial nos campos de altitude (Fig. 1a-d). Foram realizadas quatro viagens ao campo para coletas, documentação fotográfica e análise dos indivíduos em campo. Além dos materiais coletados, foram analisados materiais depositados nos seguintes herbários: BHCB, CESJ, ESA, HB, HRCB, GUA, GFJP, R, RB, SP, SPF e UEC (acrônimos segundo Thiers, continuamente atualizado). Para descrição das espécies foi utilizado Radford (1974), além da bibliografia específica para a família. As medidas apresentadas nas descrições se referem a comprimento, exceto quando especificado.

\section{Resultados e Discussão}

Foram encontradas nove espécies de Eriocaulaceae, distribuídas em quatro gêneros. Os gêneros Actinocephalus e Eriocaulon estão representados por uma espécie cada, Leiothrix por duas espécies e Paepalanthus, o gênero com maior número de espécies, está representado por cinco espécies. A maioria das espécies foi encontrada em solos úmidos, argilosos ou arenosos e apenas Eriocaulon majusculum foi encontrada crescendo em áreas brejosas da parte alta do parque.

Todas as espécies foram encontradas nos campos de altitude do Parque Nacional do Itatiaia, sendo sete delas endêmicas da Serra da Mantiqueira: Eriocaulon majusculum, Leiothrix argyroderma, $L$. beckii, Paepalanthus glabrifolius, $P$. itatiaiensis, $P$. jordanensis e P. pseudotortilis. Já Actinocephalus polyanthus apresenta ampla distribuição no Brasil e P. planifolius tem distribuição concentrada nas regiões Sul e Sudeste (BFG 2015).

As espécies que ocorrem no Parque Nacional do Itatiaia representam aproximadamente $20 \%$ das espécies que ocorrem na Mantiqueira, onde ocorrem cerca de 50 espécies (Sano \& Giulietti 2012; Trovó et al. 2015). O Parque Nacional do Itatiaia possui uma riqueza maior que a do Parque Nacional do Caparaó, onde foram encontradas somente quatro espécies (Trovó et al. 2007). Já em relação ao Parque Estadual do Ibitipoca, onde foram encontradas 22 espécies, o Parque Nacional do Itatiaia apresenta uma diversidade cerca de $50 \%$ menor. Tal fato talvez seja explicado pelo Ibitipoca estar próximo dos limites do Cerrado e possuir maior presença de quartzo no solo (Ferreira et al. 2011).

\section{Chave de identificação para as espécies de Eriocaulaceae do Parque Nacional do Itatiaia}

1. Escapos dispostos em paracládios, eixo reprodutivo presente. 1. Actinocephalus polyanthus

1'. Escapos dispostos na axila das folhas, eixo reprodutivo ausente

2. Flores diplostêmones; pétalas com glândulas 2. Eriocaulon majusculum

2'. Flores isostêmones; pétalas sem glândulas

3. Ramos estigmáticos e nectaríferos liberando-se em pontos diferentes do estilete, anteras basifixas

3'. Ramos estigmáticos e nectaríferos liberando-se na mesma altura do estilete, anteras dorsifixas

4. Escapos 20-30 cm; brácteas involucrais superando a altura do disco de flores do capítulos 3. Leiothrix argyroderma 
4'. Escapos 5,5-14 cm; brácteas involucrais igualando a altura do disco de flores do capítulos

5. Escapos coalescidos; capítulos unidos

5'. Escapos livres; capítulos solitários

6. Folha pilosa na face adaxial, com margem ciliada

6. Paepalanthus itatiaiensis

6'. Folha glabra, com margem glabra.

8. Paepalanthus planifolius

7. Brácteas involucrais castanho-claras.

7. Paepalanthus jordanensis

7'. Brácteas involucrais castanho-escuras

8. Capítulos com ca. $2 \mathrm{~mm}$ de diâmetro; brácteas florais obovais, ápice acuminado . 9. Paepalanthus pseudotortilis

8'. Capítulos com ca. $10 \mathrm{~mm}$ de diâmetro; brácteas florais oblongas, ápice arredondado 5. Paepalanthus glabrifolius

1. Actinocephalus polyanthus (Bong.) Sano, Taxon 53: 103. 2004. Fig. 1e-g

Planta $35-70 \mathrm{~cm}$ alt. Eixo reprodutivo 15-35 cm, paracládios 7-28,5 $\mathrm{cm}$, brácteas do paracládio $2,5-3 \mathrm{~cm}$, lanceoladas, glabras em ambas as faces, ciliadas na margem, ápice agudo. Folhas em roseta, $8-17 \times 0,5-1,5 \mathrm{~cm}$, lanceoladas, pilosas em ambas as faces, glabras na margem, ápice agudo. Espatas 0,5-1,5 cm, laxas, pilosas, ápice agudo. Escapos 2,5-4 cm, livres reunidos em paracládios, pilosos. Capítulos alvos, ca. $3 \mathrm{~mm}$ diâm.; brácteas involucrais castanhas, ca. $3 \mathrm{~mm}$, obovais, pilosas a glabrescentes na face abaxial, ciliadas na margem, ápice obtuso. Brácteas florais castanhas, ca. $7 \mathrm{~mm}$, oboval-elípticas, pilosas a glabrescentes na face abaxial, ciliadas na margem, ápice obtuso-arredondado. Flor isostêmone. Flor estaminada ca. $2 \mathrm{~mm}$, pedicelo ca. $0,3 \mathrm{~mm}$, com longos tricomas; sépalas castanhas, obovadas, pilosas na face abaxial, margem ciliada, ápice obtuso; tubo da corola hialino, anteras dorsifixas, pistilódios papilosos. Flor pistilada ca. 2,5 mm, séssil; sépalas castanhas, obovadas, pilosas na face abaxial, margem ciliada, ápice obtuso; pétalas hialinas, elípticas, ciliadas na margem, ápice obtuso; ramos estigmáticos filiformes, maiores que os ramos nectaríferos, liberando-se no mesmo ponto do estilete.

Comentários: Actinocephalus polyanthus é uma espécie de ampla distribuição no Brasil (BFG 2015). Foi encontrada formando grandes populações no planalto do Itatiaia, em solos argilosos e úmidos. Floresce principalmente entre os meses de novembro e março. Pode ser distinta das demais espécies que ocorrem no parque por possuir um eixo reprodutivo alongado portando paracládios laterais que sustentam os capítulos. Material examinado selecionado: Itatiaia, II.1896, E. Ule (R 47926); VI.1899, K.T. Ribeiro 197 (RFA);
IV.1929, P. Campos Porto 1915 (RB); II.1938, L. Lanstyak (RB 445598); II.1938, L. Lanstyak (RB 445601); VI.1943, F. Segadas Viana (RFA 5916); III.1945, F. Segadas Viana (RFA 811); III.1947, P. Ochionni 952 (RFA); II.1960, O.M. Barth (RFA 23036); XI.1974, N. Santos 5038 (RFA); V.1926, Mamp 4828 (R); II.1938, L. Lanstyak (RB 446387); V.1940, J.J. Sampaio (RB 62787); V.1940, J.J. Sampaio 3518 (CESJ); IV. 1942, W.D. Barros 835 (RB); I.1961, E. Fromm 155 (R); II.1967, J.C. Lindeman 4169 (RB); II.1972, S.V. de Andrade 1404 (RB); III.1976, S.V. de Andrade (RB 445570); IV.2014, S.N.S. Freitas 6 (RB).

2. Eriocaulon majusculum Ruhland in Engler, Pflanzenr. 30: 44. $1903 . \quad$ Fig.1h-j Planta $24-35 \mathrm{~cm}$ alt. Eixo reprodutivo ausente. Folhas em roseta, 16,5-20 × 0,5-1,5 $\mathrm{cm}$, lanceoladas, glabras em ambas as faces e na na margem, ápice agudo. Espatas 14,5-18 $\mathrm{cm}$, não laxas, glabras, ápice truncado. Escapos 14-20 cm, livres, glabros. Capítulos alvos, ca. 7 mm diâm.; brácteas involucrais castanho-claras, ca. 1,5 mm, ovais, glabras em ambas as faces, glabras na margem, ápice obtuso. Brácteas florais castanhas, ca. $1 \mathrm{~mm}$, oblongas, glabras em ambas as faces, glabras na margem, ápice obtuso. Flor diplostêmone. Flor estaminada ca. $3 \mathrm{~mm}$, pedicelo ca. $0,5 \mathrm{~mm}$, com longos tricomas; sépalas castanho-claras, obovadas, glabras em ambas as faces, glabras na margem, ápice arredondado; tubo da corola castanho, com glândulas na face adaxial, anteras dorsifixas. Flor pistilada ca. $3 \mathrm{~mm}$, pedicelo ca. $0,3 \mathrm{~mm}$, glabrescente; sépalas castanho-claras, lineares, glabras em ambas as faces, glabras na margem, ápice agudo; pétalas castanhas, lineares, glabras em ambas as faces, glabras na margem, ápice arredondado, com glândulas; estigmas filiformes, ramos nectaríferos ausentes. 

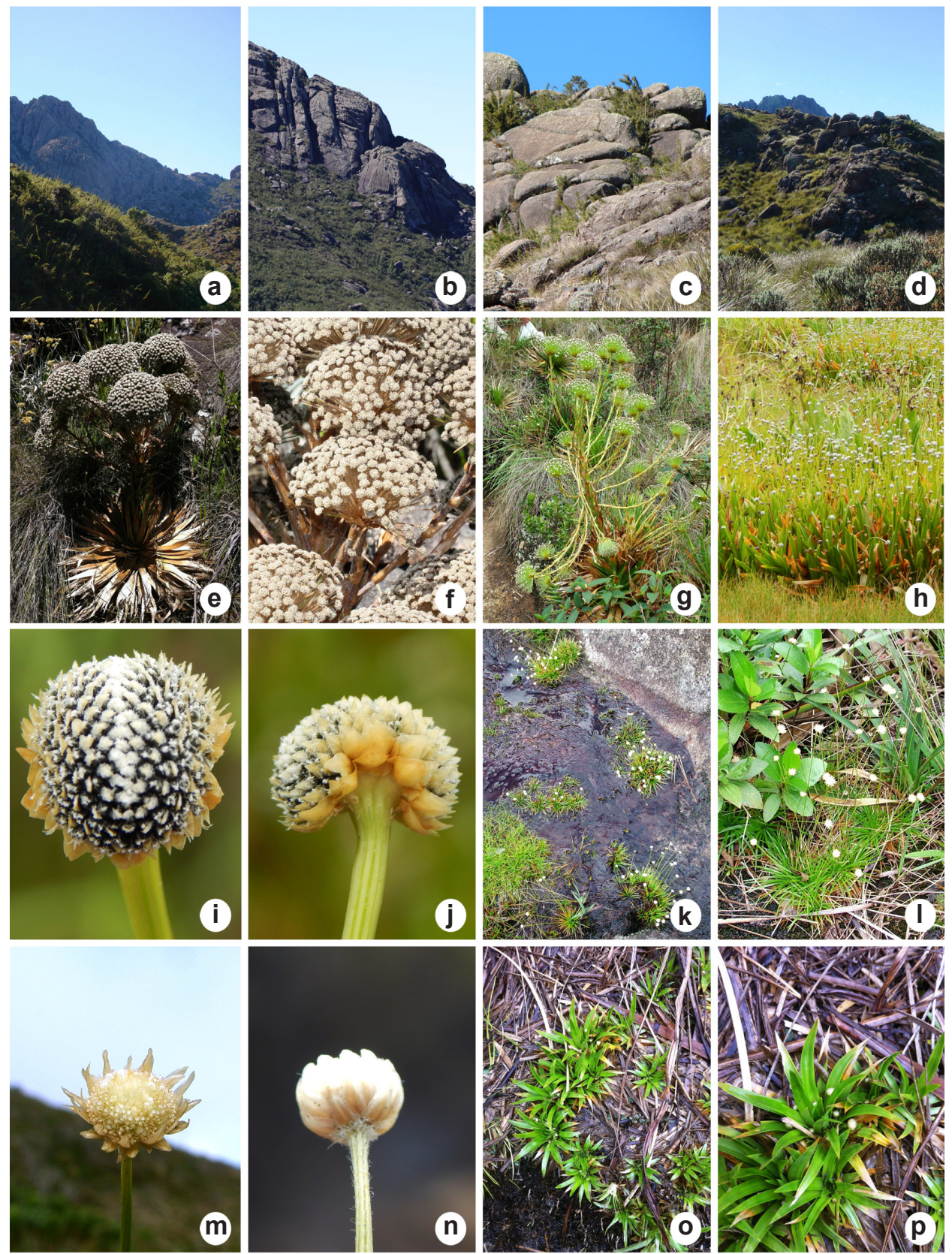

Figura 1 - Vista geral, aspectos da vegetação e espécies de Eriocaulaceae do Parque Nacional do Itatiaia, Rio de Janeiro, Brasil - a. vista geral do Maciço de Itatiaia; b. vegetação na base das Agulhas Negras; c. vegetação entre rochas no Planalto de Itatiaia; d. aspecto geral da vegetação no Planalto de Itatiaia; e. hábito de indivíduo velho de Actinocephalus polyanthus; f. detalhe da inflorescência de A. polyanthus; g. hábito de indivíduo maduro de A. polyanthus; h. hábito de Eriocaulon majusculum; i. detalhe do capítulo de E. majusculum; j. detalhe das brácteas involucrais de E. majusculum; k. população de Leiothrix argyroderma em área alagada; 1 . hábito de L. argyroderma; $\mathrm{m}$. detalhe do capítulo de L. argyroderma; $\mathrm{n}$. detalhe de brácteas involucrais e escapo de L. argyroderma; o. hábito de Leiothrix beckii; p. detalhe do hábito de L. beckii. Figure 1 - Overview, vegetation aspects, and Eriocaulaceae species from the Itatiaia National Park, Rio de Janeiro, Brazil - a. overview of the Itatiaia Massif; b. vegetation at the bottom of the Agulhas; c. vegetation between the rocks in the Itatiaia Plateau; d. general aspect of the vegetation in the Itatiaia Plateau; e. habit of an old individual of Actinocephalus polyanthus; $\mathrm{f}$. inflorescence detail of A. polyanthus; $\mathrm{g}$. habit of a mature individual of A. polyanthus; h. habit of Eriocaulon majusculum; i. capitulum detail of $E$. majusculum; $;$. involucral bracts detail of E. majusculum; $\mathrm{k}$. population of Leiothrix argyroderma in flooded area; 1 . habit of L. argyroderma; $m$. capitulum detail of L. argyroderma; n. involucral bracts and scape detail of L. argyroderma; 0 . habit of Leiothrix beckii; p. habit of L. beckii. 
Comentários: Eriocaulon majusculum é uma espécie com distribuição restrita aos estados de Minas Gerais, Rio de Janeiro e São Paulo (BFG 2015). Em Itatiaia, foram encontradas populações da espécie em solo úmido, nos brejos da parte alta do parque. Floresce nos meses de outubro a dezembro. É distinta das outras espécies do Parque Nacional do Itatiaia pela ocorrência nas partes alagadas e brejosas, por possuir flores diplostêmones com glândulas nas pétalas e longos escapos portando capítulos alvos.

Material examinado selecionado: Itatiaia, XI.1938, Markgraf 3661 (RB); XI.1964, S.V. de Andrade (RB 445578); XII.1965, S.V. de Andrade (RB 445585); IX.1975, A.M. Camerik 129 (RB); XI.1976, G. Martinelli 1085 (RB); X.1977, P.J.M. Maas 3202 (RB); X.1994, A. Piratininga 81 (RB); IV.2014, S.N.S. Freitas 5 (RB); XI.2014, S.N.S. Freitas 8 (RB).

3. Leiothrix argyroderma Ruhland in Engler, Pflanzenr. 30: 227. 1903.

Fig. 1k-n

Planta $20-30 \mathrm{~cm}$ alt. Eixo reprodutivo ausente. Folhas em roseta, 2,5-5 × 0,1-0,2 cm, lineares, glabras em ambas as faces e na margem, ápice acuminado. Espatas 4-5 cm, não laxas, glabras, ápice agudo. Escapos $20-30 \mathrm{~cm}$, livres, pilosos. Capítulos alvos, ca. $5 \mathrm{~mm}$ diâm.; brácteas involucrais superando os capítulos, castanhoclaras, ca. $2 \mathrm{~mm}$, ovais, glabras em ambas as faces, glabras na margem, ápice agudo. Brácteas florais castanho-claras, com ca. $0,3 \mathrm{~mm}$, oblongas, glabras em ambas as faces, glabras na margem, ápice agudo. Flor isostêmone. Flor estaminada ca. $2 \mathrm{~mm}$, pedicelo ca. $0,3 \mathrm{~mm}$, com longos tricomas; sépalas hialinas, ovais, glabras em ambas as faces, glabras na margem, ápice arredondado; tubo da corola hialino, anteras basifixas, pistilódios papilosos. Flor pistilada ca. $2 \mathrm{~mm}$, pedicelo ca. 0,1 $\mathrm{mm}$, glabro; sépalas hialinas, elípticas, pilosas em ambas as faces, glabras na margem, ápice agudo; pétalas hialinas, elípticas, pilosas em ambas as faces, glabras na margem, ápice agudo; ramos estigmáticos bífidos, do mesmo comprimento que os ramos nectaríferos, liberando-se em pontos diferentes do estilete.

Comentários: Leiothrix argyroderma é uma espécie restrita aos estados de Minas Gerais, Rio de Janeiro e São Paulo (BFG 2015). Em Itatiaia, foi encontrada entre fendas rochosas na parte alta do parque. Floresce nos meses de abril a julho. Diferencia-se das demais espécies ocorrentes no Parque Nacional do Itatiaia por possuir escapo piloso e brácteas maiores que o capítulo.
Material examinado selecionado: Itatiaia, VII.1901, M. Julio (R 47874); XI.1938, Markgraf (CESJ 3492); III.1945, F. Segadas Viana (RFA 23057); XI.1945, J.J. Sampaio (RB 445602); V.1950, A.C. Brade 20369 (RB); II.1958, A. Castellanos 21899 (R); IV.1977, L. Emygdio 1440 (R); VI.1978, S.F. Lua 16 (RB); II.1990, L. Clark 661 (RB); IV.1995, J.M.A. Braga 2333 (RB); IX.1995, J.M.A. Braga 2851 (RB); IV.2014, S.N.S. Freitas 4 (RB); XI.2014 S.N.S. Freitas 12 (RB).

4. Leiothrix beckii Ruhland in Engler, Pflanzenr. 30: 226. 1903.

Figs. 1o,p; 2a,b

Planta $15-17,5 \mathrm{~cm}$ alt. Eixo reprodutivo ausente. Folhas em roseta, $2-7 \times 0,1-0,3 \mathrm{~cm}$, lanceoladas, glabras em ambas as faces, ciliadas na margem, ápice agudo. Espatas 0,5-1 cm, não laxas, pilosas, ápice agudo. Escapos 5,5-14 cm, livres, pilosos. Capítulos alvos, ca. $4 \mathrm{~mm}$ diâm.; brácteas involucrais igualando os capítulos, castanho claras, ca. $3 \mathrm{~mm}$, ovais, pilosas em ambas as faces, glabras na margem, ápice agudo. Brácteas florais castanhas, ca. $2 \mathrm{~mm}$, elípticas, glabras em ambas as faces, ciliadas na margem, ápice agudo. Flor isostêmone. Flor estaminada ca. $2 \mathrm{~mm}$, pedicelo ca. $0,5 \mathrm{~mm}$, com longos tricomas; sépalas hialinas, obovadas, pilosas em ambas as faces, ciliadas na margem, ápice obtuso; tubo da corola castanhoclaro, anteras basifixas, pistilódios papilosos. Flor pistilada ca. 2,5 $\mathrm{mm}$, pedicelo ca. $0,2 \mathrm{~mm}$, glabro; sépalas castanho-claras, obovadas, pilosas em ambas as faces, ciliadas na margem e com ápice obtuso; pétalas castanho-claras, elípticas, pilosas em ambas as faces, ciliadas na margem, ápice agudo; ramos estigmáticos bífidos, do mesmo comprimento que os ramos nectaríferos, liberandose em pontos diferentes do estilete.

Comentários: Leiothrix beckii é uma espécie restrita aos estados de Minas Gerais, Rio de Janeiro e São Paulo (BFG 2015). Em Itatiaia, foram encontradas populações ocorrendo em solos arenosos na beira das trilhas. Floresce principalmente nos meses de maio e junho. Diferese das outras espécies do Parque Nacional do Itatiaia, por apresentar curtos escapos envolvidos por espatas que geralmente são do mesmo comprimento que as folhas.

Material examinado selecionado: Itatiaia, II.1950, A.C. Brade 202219 (RB); V.1950, F. Segadas Vianna 5029 (RFA); V.1950, F. Segadas Vianna 5033 (RFA); VI.1950, A.C. Brade 20367 (RB); XII.1960, B. Lutz (R 111785); VI.1975, A.M. Camerik 131 (RB); VI.1975, A.M. Camerik 134 (RB); XI.1976, G. Martinelli 1089 (RB); X.1977, P.J. Maas 3170 (RB); IV.1995, J.M.A. Braga 2310 (RB); XI.2014, S.N.S. Freitas 13 (RB). 

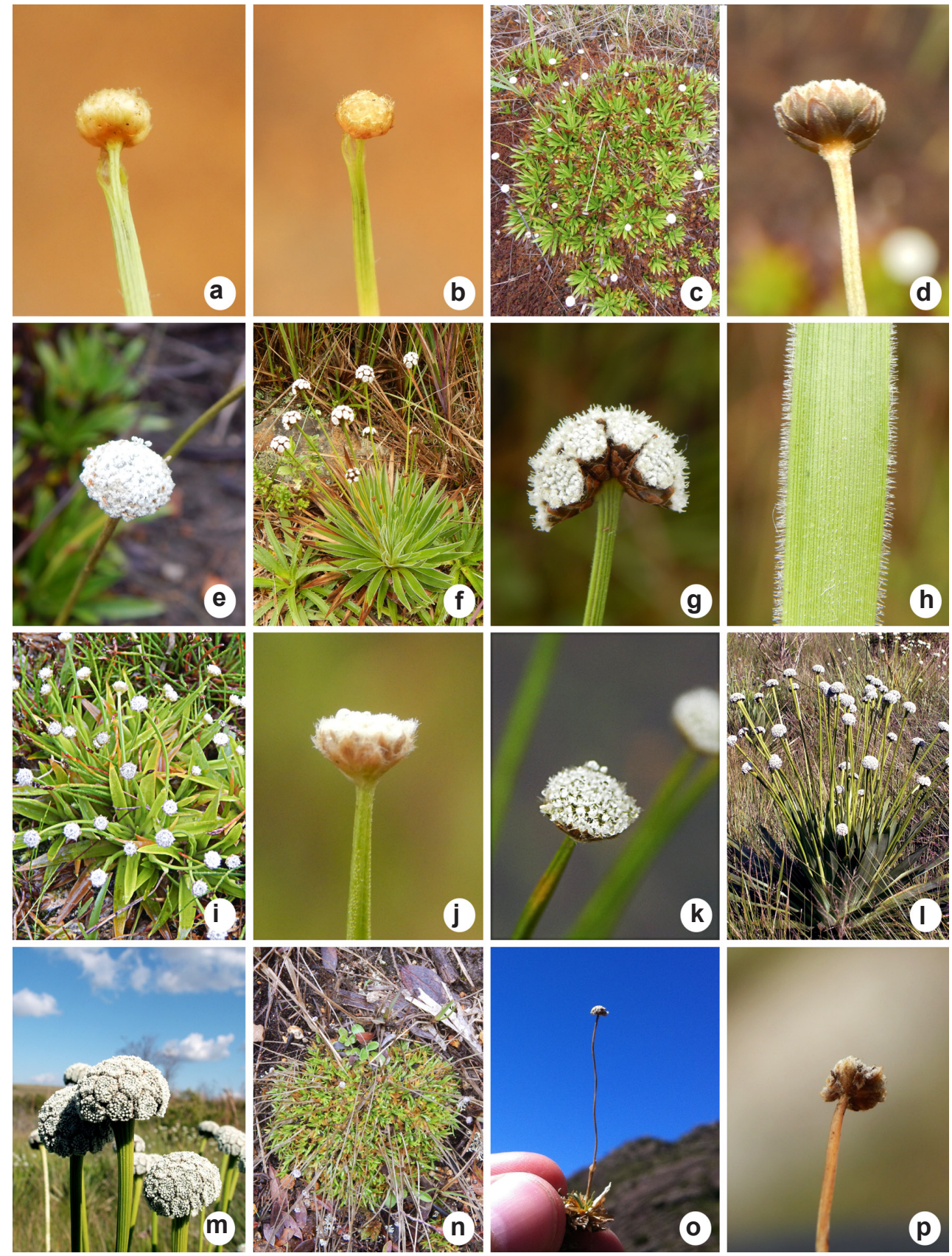

Figura 2 - Espécies de Eriocaulaceae do Parque Nacional do Itatiaia, Rio de Jabeiro, Brasil -a. detalhe das brácteas involucrais de Leiothrix beckii; b. detalhe do capítulo de L. beckii; c. hábito de Paepalanthus glabrifolius; d. detalhe das brácteas involucrais de P. glabrifolius; e. detalhe do capítulo de P. glabrifolius; f. hábito de Paepalanthus itatiaiensis; g. detalhe dos capítulos coalescidos de $P$. itatiaiensis; h. detalhe da margem da folha ciliada de $P$. itatiaiensis; i. hábito de Paepalanthus jordanensis; j. detalhe das brácteas involucrais de $P$. jordanensis; $\mathrm{k}$. detalhe do capítulo de $P$. jordanensis; 1 . hábito de Paepalanthus planifolius; $\mathrm{m}$. detalhe dos capítulos coalescidos de P. planifolius; n. hábito de Paepalanthus pseudotortilis; o. indivíduo isolado de P. pseudotortilis; p. detalhe das brácteas involucrais de P. pseudotortilis.

Figure 2 - Eriocaulaceae species from the Itatiaia National Park, Rio de Janeiro, Brazil -a. involucral bracts detail of Leiothrix beckii; b. capitulum detail of $L$. beckii; c. habit of Paepalanthus glabrifolius; d. involucral bracts detail of P. glabrifolius; e. capitulum detail of $P$. glabrifolius; f. habit of Paepalanthus itatiaiensis; $\mathrm{g}$. coalescent capitula detail of $P$. itatiaiensis; h. ciliate leaf margin detail of P. itatiaiensis; i. habit of Paepalanthusjordanensis; j. involucral bracts detail of $P$. jordanensis; $\mathrm{k}$. capitulum detail of $P$. jordanensis; 1 . habit of de Paepalanthus planifolius; $\mathrm{m}$. coalescent capitula detail of P. planifolius; $\mathrm{n}$. habit of Paepalanthus pseudotortilis; o. isolated individual of $P$. pseudotortilis; $\mathrm{p}$. involucral bracts detail of P. pseudotortilis. 
5. Paepalanthus glabrifolius Ruhland in Engler, Pflanzenr. 30: 139. 1903.

Fig. 2c-e

Planta $7-17 \mathrm{~cm}$ alt. Eixo reprodutivo ausente. Folhas em roseta, 0,5-5 × 0,1-0,5 cm, lanceoladas, glabras em ambas as faces e na margem, ápice agudo. Espatas $2-5,5 \mathrm{~cm}$, não laxas, glabras, ápice obtuso. Escapos 5-16 cm, livres, glabros. Capítulos alvos, ca. 10 mm diâm.; brácteas involucrais castanho-escuras, ca. $3 \mathrm{~mm}$, elípticas, pilosas em ambas as faces, ciliadas na margem, ápice apiculado. Brácteas florais castanhas, ca. $3 \mathrm{~mm}$, oblongas, pilosas ambas as faces, ciliadas na margem, ápice arredondado. Flor isostêmone. Flor estaminada ca. $3 \mathrm{~mm}$, pedicelo ca. $0,5 \mathrm{~mm}$, com longos tricomas; sépalas castanhas, oblongas, pilosas em ambas as faces, ciliadas na margem, ápice arredondado; tubo da corola castanho, anteras dorsifixas, pistilódios papilosos. Flor pistilada ca. $3 \mathrm{~mm}$, pedicelo ca. 0,5 mm, piloso; sépalas castanhas, oblongas, pilosas em ambas as faces, ciliadas na margem, ápice arredondado; pétalas castanhas, obovadas, pilosas em ambas as faces, ciliadas na margem, ápice obtuso; ramos estigmáticos filiformes, bífidos, maiores que os ramos nectaríferos, liberando-se no mesmo ponto do estilete.

Comentários: Paepalanthus glabrifolius é uma espécie restrita aos estados do Rio de Janeiro e São Paulo (BFG 2015). Em Itatiaia, foi encontrada formando touceiras, em pequenas populações, em solos úmidos da parte alta. Tem pico de floração no mês de novembro. Difere-se das espécies mais semelhantes encontradas no Parque Nacional do Itatiaia por possuir hábito gregário, capítulos relativamente grandes com brácteas involucrais castanhas.

Material examinado selecionado: Itatiaia, XI.1945, J.J. Sampaio (RB 445600); XI.1965, J.J. Sampaio (RB 446386); XI.2014, S.N.S. Freitas 11 (RB); s.d., C. Porto 2095 (RB).

\section{Paepalanthus itatiaiensis Ruhland in Engler,} Pflanzenr. 30: 211. 1903.

Fig. 2f-h

Planta 16-27 cm alt. Eixo reprodutivo ausente. Folhas em roseta, 15,5-19 ×0,5-1 cm, lanceoladas, pilosas na face adaxial, ciliadas na margem, ápice agudo. Espatas $3-5 \mathrm{~cm}$, laxas, glabras, ápice agudo. Escapos 7-9 cm, coalescidos, pilosos. Capítulos alvos, ca. $10 \mathrm{~mm}$ diâm.; brácteas involucrais castanhas, ca. $3 \mathrm{~mm}$, elípticas, glabras em ambas as faces, ciliadas na margem, ápice agudo. Brácteas florais castanhas, ca. $2 \mathrm{~mm}$, elípticas, glabras em ambas as faces, ciliadas na margem, ápice agudo. Flor isostêmone. Flor estaminada ca. $3 \mathrm{~mm}$, pedicelo ca. $0,5 \mathrm{~mm}$, com longos tricomas; sépalas castanhas, obovadas, glabras em ambas as faces, ciliadas na margem, ápice agudo; tubo da corola hialino, anteras dorsifixas, pistilódios papilosos. Flor pistilada ca. 3,5 mm, séssil, glabra; sépalas castanhas, obovadas, glabras em ambas as faces, ciliadas na margem, ápice agudo; pétalas hialinas, elípticas, glabras em ambas as faces, ciliadas na margem, ápice agudo; ramos estigmáticos bífidos, do mesmo tamanho que os ramos nectaríferos, liberando-se no mesmo ponto do estilete.

Comentários: Paepalanthus itatiaiensis é uma espécie restrita aos estados de Minas Gerais, São Paulo e Rio de Janeiro (BFG 2015). Em Itatiaia, foi encontrada formando grandes populações em solos arenosos, em toda a extensão da parte alta do parque. Floresce nos meses de outubro a março. Diferencia-se das demais espécies do parque por possuir capítulos unidos e folhas densamente ciliadas.

Material examinado selecionado: Itatiaia, X.1903, A. Silveira (R 47910); II.1913, A. Silveira (R 607); I.1947, A.P. Duarte 845 (RFA); V.1950, F. Segadas Vianna 1130 (RFA); XI.1953, F. Segadas Vianna 1128 (R); XI.1953, F. Segadas Vianna 1130 (RFA); XI.1953, F. Segadas Vianna 1131 (RFA); XI.1954, A.C. Brade (RB 445595); II.1958, A. Castellanos 21848 (R); II.1958, A. Castellanos 22897 (R); IV.1959, L. Scheinvar 68 (R); XI.1964, S.V. de Andrade 284 (RB); XII.1965, S.V. de Andrade (RB 445590); V.1975, A.M. Camerik 74 (RB); X.1977, L.R. Landrum 2104 (RB); X.1977, P.J. Maas 3181 (RB); X.1977, V.F. Ferreira 234 (RB); I.1979, P. Occhioni 8696 (RFA); IX.1980, J.G. Stutts 831 (NY); XII.1983, L. Sylvestre 26 (R); II.1990, L. Clark 659 (RB); III.1995, J.M.A. Braga 2249 (RB); I.1996, J.M.A. Braga 3183 (RB); I.2003, V.F. Mansano 186 (RB); III.2006, V.F. Mansano 6-298 (RB); IV.2014, S.N.S. Freitas 3 (RB); XI.2014, S.N.S. Freitas 9 (RB).

7. Paepalanthus jordanensis Silveira, Floral. Mont. 1: 92. 1928.

Fig. 2i-k

Planta 9-18 cm alt. Eixo reprodutivo ausente. Folhas em roseta, 2-4,5 × 0,3-0,5 cm, lanceoladas, glabras em ambas as faces, ciliadas na margem, ápice agudo a acuminado. Espatas 2-3 cm, laxas, glabras, ápice laxo. Escapos 10-14 cm, livres, glabros. Capítulos alvos, ca. 5 mm diâm.; brácteas involucrais castanho-claras, ca. $2 \mathrm{~mm}$, elípticas, glabras em ambas as faces, ciliadas na margem, ápice obtuso. Brácteas florais castanhas, ca. $2 \mathrm{~mm}$, lanceoladas, glabras em ambas as faces, ciliadas na margem, ápice obtuso. Flor isostêmone. 
Flor estaminada ca. $2 \mathrm{~mm}$, pedicelo ca. 0,5 $\mathrm{mm}$, com longos tricomas; sépalas castanhas, obovadas, glabras em ambas as faces, ciliadas na margem, ápice obtuso; tubo da corola castanho, anteras dorsifixas, pistilódios papilosos. Flor pistilada ca. $2 \mathrm{~mm}$, pedicelo ca. $0,3 \mathrm{~mm}$, glabro; sépalas castanho-claras, obovadas, glabras em ambas as faces, ciliadas na margem, ápice agudo; pétalas hialinas, oblongas, glabras em ambas as faces, ciliadas na margem, ápice agudo; ramos estigmáticos filiformes, do mesmo comprimento que os ramos nectaríferos, liberando-se no mesmo ponto do estilete.

Comentários: Paepalanthus jordanensis é uma espécie com distribuição restrita aos estados de Rio de Janeiro e São Paulo (BFG 2015). Em Itatiaia, foi encontrada em solos úmidos e argilosos. Floresce principalmente entre os meses de julho e dezembro. Difere-se das demais espécies do parque pelo hábito geralmente solitário, em solos úmidos, e por possuir brácteas involucrais castanho-claras.

Material examinado selecionado: Itatiaia, XII.1983, L. Sylvestre 628 (R); IV.2014, S.N.S. Freitas 3 (RB); XI.2014, S.N.S. Freitas 7 (RB).

8. Paepalanthus planifolius (Bong.) Körn. in Mart. \& Eichler, Fl. bras. 3: 413. 1863.

Fig. 21,m

Planta 15-40 $\mathrm{cm}$ alt. Eixo reprodutivo ausente. Folhas em roseta, 7-30 × 0,5-3 cm, lanceoladas, glabras em ambas as faces, ciliadas na margem, ápice agudo. Espatas 5-20,5 cm, estreitas, glabras, ápice truncado. Escapos 7-38 $\mathrm{cm}$, coalescidos, glabros. Capítulos alvos, ca. $1 \mathrm{~cm}$ diâm.; brácteas involucrais castanhas, ca. $3 \mathrm{~mm}$, oblongas, pilosas em ambas as faces, ciliadas na margem, ápice agudo. Brácteas florais castanhas, com ca. $1 \mathrm{~mm}$, obovadas, pilosas em ambas as faces, ciliadas na margem, ápice agudo. Flor isostêmone. Flor estaminada ca. 1,5 mm, pedicelo ca. $0,5 \mathrm{~mm}$, com longos tricomas; sépalas castanhas, obovadas, pilosas em ambas as faces, ciliadas na margem, ápice obtuso; tubo da corola hialino, anteras dorsifixas, pistilódios papilosos. Flor pistilada ca. $1,5 \mathrm{~mm}$, pedicelo ca. 0,5 mm, piloso; sépalas castanhas, obovadas, pilosas em ambas as faces, ciliadas na margem, ápice obtuso; pétalas douradas, oblongas, glabras em ambas as faces, ciliadas na margem, ápice acuminado; ramos estigmáticos filiformes, do mesmo comprimento que os ramos nectaríferos, liberando-se no mesmo ponto do estilete.
Comentários: Paepalanthus planifolius é uma espécie com ampla distribuição nas regiões Sul e Sudeste (BFG 2015). Em Itatiaia, sua ocorrência está ligada à parte alta, onde ocorre com baixa frequência em solos argilosos e úmidos. Floresce nos meses de agosto e dezembro. Diferencia-se das demais espécies do parque por possuir capítulos unidos e margem da folha glabra. Material examinado selecionado: Itatiaia, V.1902, $P$. Dusen 255 (R); I.1947, A. Duarte 3521 (CESJ); VI.1970, T. Hoyama \& P.G. Windisch 13695 (NY).

\section{Paepalanthus pseudotortilis Ruhland in Engler, Pflanzenr. 30: 155. 1903. \\ Fig. 2n-p}

Planta 6,5-12 cm alt. Eixo reprodutivo ausente. Folhas em roseta, 0,3-0,5 × 0,1-0,2 $\mathrm{cm}$, lineares, glabras em ambas as faces e na margem, ápice arredondado. Espatas 0,5-1 cm, não laxas, glabras, ápice agudo. Escapos 3-9,5 cm, livres, glabros. Capítulos alvos, ca. 2 mm diâm.; brácteas involucrais castanho-escuras, ca. 1,5 $\mathrm{mm}$, lineares, pilosas em ambas as faces, ciliadas na margem, ápice acuminado. Brácteas florais castanhas, ca. $1 \mathrm{~mm}$, obovadas, pilosas em ambas as faces, ciliada na margem, ápice acuminado. Flor isostêmone. Flor estaminada ca. $1 \mathrm{~mm}$, pedicelo ca. 0,2 mm, longos tricomas; sépalas castanhas, obovadas, pilosas em ambas as faces, ciliadas na margem, ápice acuminado; tubo da corola castanho-claro, anteras dorsifixas, pistilódios papilosos. Flor pistilada ca. $1 \mathrm{~mm}$, séssil; sépalas castanhas, obovadas, pilosas em ambas as faces, ciliadas na margem, ápice acuminado; pétalas castanho-claras, obovadas, pilosas em ambas as faces, ciliadas na margem, ápice obtuso; ramos estigmáticos bífidos, do mesmo comprimento que os ramos nectaríferos, liberando-se no mesmo ponto do estilete.

Comentários: Paepalanthus pseudotortilis é uma espécie restrita aos estados de Minas Gerais, Rio de Janeiro e São Paulo (BFG 2015). Em Itatiaia, foi encontrada em pequenas populações em solos arenosos e argilosos. Floresce principalmente entre os meses de dezembro e março. Difere-se das demais espécies do parque por possuir pequeno porte, hábito gregário e folhas diminutas com ápice arredondado.

Material examinado selecionado: Itatiaia, III.1937, A.C. Brade 3473 (CESJ); XII.1941, W.D. de Barros 513 (RB); II.1945, A.C. Brade 17413 (RB); II.1950, A.C. Brade 20220 (RB); I.1969, S.V. de Andrade (RB 445594); II.1995, J.M.A. Braga 2052 (RB); I.1996, J.M.A. Braga 3224 (RB); IV.2014, S.N.S. Freitas 3 (RB); XI.2014, S.N.S. Freitas 10 (RB). 


\section{Agradecimentos}

Os autores agradecem aos curadores dos herbários visitados e às seguintes agências de fomento: Alexander von Humboldt Foundation, FAPERJ (E-26/110.031/2011, E-26/111.392/2012, E-26/111010.001.392/2014 - BIOTA); CNPq (proc. 470349/2013-1).

\section{Referências}

BFG - The Brazil Flora Group (2015) Growing knowledge: an overview of seed plant diversity in Brazil. Rodriguésia 66: 1085-1113.

Brade AC (1956) A flora do Parque Nacional do Itatiaia. Boletim n ${ }^{\circ}$ 5. Ministério da Agricultura, Serviço Florestal, Rio de Janeiro. 137p.

Costa FN, Trovó M \& Sano PT (2008) Eriocaulaceae na Cadeia do Espinhaço: riqueza, endemismo e ameaças. Megadiversidade 4: 117-125.

Ferreira CSAM, Trovó M \& Forzza RC (2011) A família Eriocaulaceae no Parque Estadual do Ibitipoca, Minas Gerais, Brasil. Boletim de Botânica da Universidade de São Paulo 29: 19-35.

Giulietti AM \& Hensold N (1990) Padrões de distribuição geográfica dos gêneros de Eriocaulaceae. Acta Botanica Brasilica 4: 133159.

Giulietti AM, Hensold N, Parra LR, Andrade MJG, van den Berg C \& Harley RM (2012) The synonymization of Philodice with Syngonanthus (Eriocaulaceae). Phytotaxa 60: 50-56.

Hensold N (1999) Eriocaulaceae. In: Steyermark JA, Berry PE, Yatskievych K \& Holst BK (eds.) Flora of Venezuelan Guayana. Vol. 5. Missouri Botanical Garden Press, Saint-Louis, Missouri. Pp. 1-58.
ICMBIO (2015) Instituto Chico Mendes de Conservação da Biodiversidade. Disponível em $<$ http://www. icmbio.gov.br/parnaitatiaia/>. Acesso em 2 março 2015.

Koernicke F (1863) Eriocaulaceae. In: Martius KFP \& Eichler AW (eds.) Flora brasiliensis. Tipografia Regia, Munique. Vol. 3, pars 1, pp. 271-508.

Radford AE (1974) Vascular plant systematics. Harper \& Row, New York. 891p.

Ruhland W (1903) Eriocaulaceae. In: Engler A (ed.) Das Pflanzenreich. Regni vegetabilis conspectus IV. 30. Wilhelm Engelmann, Leipzig. Pp. 1-294.

Sano PT \& Giulietti AM (2012) Eriocaulaceae. In: Wanderley MGL, Shepherd GJ, Melhem TS, Guilietti AM \& Martins SE. Flora fanerogâmica do estado de São Paulo. Instituto de Botânica, São Paulo. Vol. 7, pp. 173-200.

Stützel T (1998) Eriocaulaceae. In: Kubitzki K (ed.) The families and genera of vascular plants IV flowering plants monocotyledons - Alismatanae and Commelinanae (except Gramineae). Springer - Verlag, Berlin. Pp. 197-207.

Thiers B [continuamente atualizado] Index Herbariorum. Disponível em <http://sweetgum.nybg.org/ih>. Acesso em 2 março 2015.

Trovó M, Echternacht L, Costa FN, Giulietti AM \& Sano PT (2015) Nomenclatural and taxonomy notes on Eriocaulaceae from the Atlantic Forest, Brazil. Phytotaxa 205: 249-258.

Trovó M, Sano PT, Costa FN \& Giulietti AM (2007) Flora fanerogâmica do Parque Nacional do Caparaó: Eriocaulaceae. Pabstia 17: 2-8

Veloso HP; Rangel Filho ALR \& Lima JCA (1991) Classificação da vegetação brasileira, adaptada a um sistema universal. IBGE - Departamento de Recursos Naturais e Estudos Ambientais, Rio de Janeiro. 123p. 